\title{
Unternehmen \\ engagiert sich für die Resistenzdiagnostik
}

Die Carpegen GmbH (www.carpegen.de), Entwickler des Parodontitis-Testverfahrens Carpegen Perio Diagnostik, beteiligt sich an einem neuen Verbund-Forschungsprojekt zur schnellen Identifizierung von Antiobiotika-Resistenzen. Im Forschungsprojekt „PathoSept“, das vom Fraunhofer-Institut für Angewandte Informationstechnik (FIT) koordiniert wird, entwickelt das Unternehmen gemeinsam mit Partnern ein nutzerfreundliches Komplettsystem für den Nachweis von Sepsis-

Erregern mit Resistenzen gegen verschiedene Antibiotika. Bisherige Nachweise beruhen auf Kulturverfahren, die oft mehrere Tage in Anspruch nehmen. Das Forschungspro-

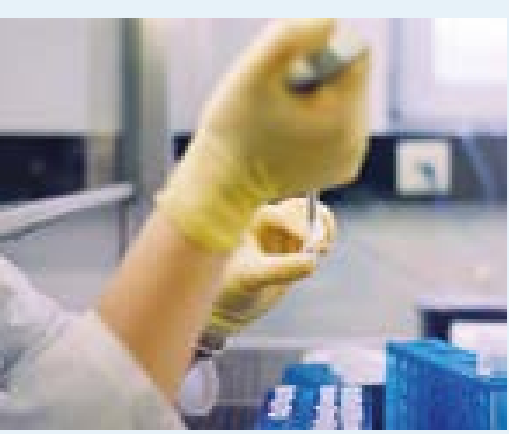

jekt, an dem sich neben dem FraunhoferInstitut FIT und Carpegen 2 weitere Industriepartner und 2 Universitätskliniken aus Nordrhein-Westfalen beteiligen, startet im Juni 2016. Das Projektvolumen beläuft sich auf 3,5 Mio $€$. In der zahnärztlichen Praxis ist die schnelle und zuverlässige Erkennung von Erregern mit Testverfahren wie Carpegen Perio Diagnostik bereits gang und gäbe. Es kommt darauf an, in jedem Einzelfall genau das richtige Antibiotikum zu wählen. Hier will das Unternehmen Zahnärzte besser unterstützen: Die Perio-Diagnostik bestimmt die für eine Parodontitis verantwortlichen pathogenen Bakterien und gibt Auskunft über die individuell wirksame antibiotische Therapie. Diese liegt in Form eines konkreten Therapievorschlags dem Ergebnis bei. So erhält der Zahnarzt zusätzliche Sicherheit in der Therapieplanung, um den Behandlungserfolg zu verbessern und zugleich Fehl- bzw. Übertherapien und damit die Entstehung neuer Resistenzen zu vermeiden. 